\title{
Modeling and Analysis of Low Frequency Noise in Ion-Field-Effect Transistors Sensors
}

\author{
Jihen Chermiti1,2, Sawsen Azzouzi1,2, Mounir Ben Ali1,2*, Mhamed Trabelsi', \\ Abdelhamid Errachid ${ }^{3}$ \\ ${ }^{1}$ Higher Institute of Applied Sciences and Technology of Sousse, University of Sousse, Sousse, Tunisia \\ ${ }^{2}$ Laborory Materials Molecules and Applications, University of Carthage, IPEST, Tunis, Tunisia \\ ${ }^{3}$ Institute of Analytical Sciences of Lyon, Université Claude Bernard Lyon 1, Lyon, France \\ Email: ${ }^{*}$ mounirbenali@yahoo.com
}

Received 14 April 2014; revised 13 May 2014; accepted 12 June 2014

Copyright (C) 2014 by authors and Scientific Research Publishing Inc.

This work is licensed under the Creative Commons Attribution International License (CC BY).

http://creativecommons.org/licenses/by/4.0/

(c) (i) Open Access

\begin{abstract}
Ions Sensitive Field Effect Transistors (ISFETs) are becoming the platform sensors for important chemical and biomedical applications. However, the accuracy of ISFET output measurement is greatly affected by the presences of low-frequency noise, drift and slow response of the device. This requires more safety in measured results and the tools of analysis. In this paper, we present fundamental limits on the sensitivity of ISFETs micro-sensors, arising from intrinsic and extrinsic noise sources. We developed an algorithm in MATLAB in order to model the frequency analysis of the $1 / f$ noise in ISFET sensor using Hooge theory. We have shown that the $1 / f$ noise of the ISFETs sensors is due to both the electrochemical system (pH solution) and the MOS component (canal size, insulator thickness). The temperature effect on the ISFET noise and the signal conditioning are also performed.
\end{abstract}

\section{Keywords}

Top-Spice Modeling, Ion Sensitive Field Effect Transistor, Low-Frequency Noise

\section{Introduction}

In the last decade, Ion Sensitive Field Effect Transistors (ISFETs), originally introduced by Bergveld [1], have been under extensive study because of rapid response, small size, as well as applicability of semiconductor and clear operation principle based on site binding theory [2] [3]. For many years, numerous studies on different sources of ISFET noise were reported [4] [5] and thereafter an important development has already been made

\footnotetext{
${ }^{*}$ Corresponding author.
}

How to cite this paper: Chermiti, J., Azzouzi, S., Ben Ali, M., Trabelsi, M. and Errachid, A. (2014) Modeling and Analysis of Low Frequency Noise in Ion-Field-Effect Transistors Sensors. Modeling and Numerical Simulation of Material Science, 4, 119-127. http://dx.doi.org/10.4236/mnsms.2014.43013 
regarding the ISFET noise reduction and drift compensation technique in different circuits and experimental levels [6]-[9]. The study of noise in ISFETs is important for the reason that any source of noise present in the sensor imposes a fundamental limit to the accuracy of measurements and, therefore, the sensitivity of ISFETs is limited by the noise sensor. While noise studies were largely established in MOSFETs, the research of ISFETs noise was very limited. An ISFET sensor has several intrinsic and extrinsic sources noises. The intrinsic noise is generated by the electronic device itself. Since ISFET is essentially a MOS structure, the noise sources of the MOS transistor are present in the noise ISFET. Electrochemical noise is produced by ion-membrane interactions, in the liquid and the reference electrode.

In several works [5] [10] [11], it is believed that the presences of $1 / f$ low-frequency noise in ISFET sensors are mostly contributed by the FET structure of the device, which is dominated by the Insulator-Semiconductor interface [12]. More the $\mathrm{pH}$-dependent $1 / f$ electrochemical noise in ISFET is considered to be negligible in some device [4] [10]. In this work, we used a MATLAB program to prove that many parameters can affect the $1 / f$ noise in ISFET devices as well as the $\mathrm{pH}$ solution. The goal of the modeling consists to predict the operating ISFET system as function as technical parameters defining the detection system.

Contrary to previous work [12], we found that for frequency range $<1 \mathrm{~Hz}$ [13], the $\mathrm{pH}$ solution has a significant effect on the $1 / f$ noise. More the $1 /$ f noise of ISFET can be influenced par other parameters like the insulator thickness and the channel size. Additional, the modeling of temperature contribution in the spectacle density of $1 / f$ noise in ISFET and afterward are investigated in our present work.

\section{Modeling Setup}

The 1/f noise in MOSFETs has been under investigation for many years. Two different theories have been proposed to explain the physical origins of 1/f noise: number fluctuation [14] [15] and mobility fluctuation [16] [17]. These two theories are based on the fluctuation of the conductivity of MOS transistors that is:

$$
\sigma=\mu n q
$$

where $\mu$ and $n$ are respectively the mobility and the concentration of the carriers. Hence, from Equation (1) it is clear that a fluctuation of the conductivity is induced either by a fluctuation of the number of carriers (Worther model) [14] [15] or a fluctuation in the channel mobility (Hooge model) [15] [16]. In our work we used the Hooge model which defines the normalized drain current spectral density in ohmic operation by the equation below [18] [19]:

$$
\frac{S_{I_{d}}}{I_{d}^{2}}=\frac{q \alpha_{H}}{f L^{2}} \mu_{e f f} \frac{V_{d}}{I_{d}}
$$

where $f$ is the frequency and $\alpha_{H}$ is the Hooge parameter $\left(a_{H} \approx 10^{-5}\right)$.

Another way to express the noise is to calculate the power spectral density of the gate voltage witch given by [20]:

$$
S_{V_{g}}=\frac{S_{I_{d}}}{I_{d}^{2}} \frac{I_{d}^{2}}{g_{m}^{2}}
$$

The ISFET parameters used in our modeling process are these same of ISFET device manufactured at the Laboratoire d'Analyse et d'Architecture des Systémes (LAAS) in Toulouse, France [21]. These devices are n-type enhancement mode transistors with the channel size $800 \times 40 \mu \mathrm{m}$, the thickness $\mathrm{SiO}_{2} / \mathrm{Si}_{3} \mathrm{~N}_{4}$ insulator Tox $=100 \mathrm{~nm}$ and the doping substrate Nsub $=3.27 \times 10^{15}$. The silanol and amine sites are respectively $3 \times 10^{14}-2$ $\times 10^{14} \mathrm{~cm}^{-2}$.

\section{Results and Discussion}

\subsection{Dependence of $1 / f$ Noise on $\mathrm{pH}$ Solution}

The modeled ISFET has a channel width of $800 \mu \mathrm{m}$, a length of $40 \mu \mathrm{m}$ and an insulator thickness of $100 \mathrm{~nm}$. The micro-sensor is biased in the strong inversion region at a voltage $\mathrm{Vds}=1 \mathrm{~V}$. Figure 1 shows the noise spectrum of the drain current Sid for different $\mathrm{pH}$ solution (from $\mathrm{pH}=1$ to $\mathrm{pH}=14$ ) and at temperature of $25^{\circ} \mathrm{C}$. 


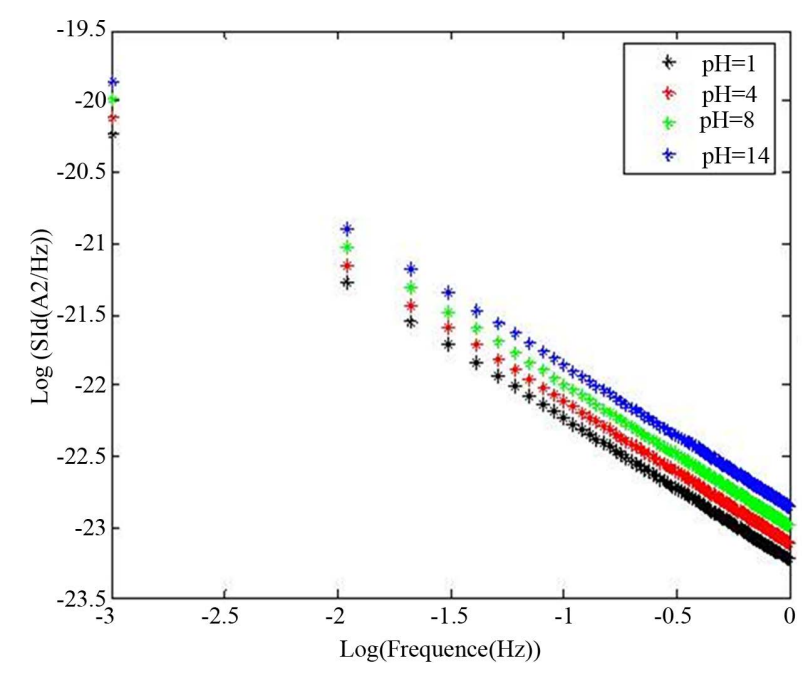

Figure 1. The noise spectral density of an ISFET at different $\mathrm{pH}(\mathrm{pH}=1,4,8$ and 12).

As it can be shown the level of $1 / f$ noise increases by increasing the $\mathrm{pH}$ solution. This modeling result is in good agreement with experimental results found in [22]. The 1/f noise dependence on the $\mathrm{pH}$ buffer is correlated to the ionic conductivity of the electrolyte [22]. The source of this noise is probably defined as the Brownian noise which is believed to be originated from the electrode-electrolyte structure of the ISFET. The origin of noise in electrode-electrolyte systems can be divided into two categories, namely, the thermal equilibrium noise and non equilibrium noise [11] [22]. The thermal equilibrium fluctuations are the only source of noise in the equilibrium condition where as recombination and generation of charged particle is the main cause of the non-equilibrium fluctuation [11]. Modeling results shows that the $1 / f$ noise is more significant at low frequencies $f<40 \mathrm{MHz}$, beyond the white noise that is dominant. The figure below illustrates the evolution of the $1 / f$ noise towards the $\mathrm{pH}$ solution for three different frequencies $f=10 \mathrm{MHz}, 100 \mathrm{MHz}$ and $1 \mathrm{~Hz}$.

In Figure 2 we note at $f=10 \mathrm{MHz}$ the noise increase with $\mathrm{pH}$ solution linearly. Increasing the frequency the linear line slop decreases. From $1 \mathrm{~Hz}$ the effect of $\mathrm{pH}$ on the noise is practically negligible. The modeling result in Figure 3 confirms that the measured ISFET 1/f noise is generated by both the electrochemical system and the FET devices.

\subsection{Influence of Channel Size}

In order to investigate the dependence of $1 / f$ noise towards the channel size of MOS structure [23] [24], we modeled the noise at different channel lengths $(\mathrm{L}=20 \mu \mathrm{m}, 30 \mu \mathrm{m}, 40 \mu \mathrm{m}$ and $\mathrm{W}=800 \mu \mathrm{m})$ and for different channel width ( $\mathrm{W}=600 \mu \mathrm{m}, 700 \mu \mathrm{m}, 800 \mu \mathrm{m}$ and $\mathrm{L}=30 \mu \mathrm{m})$.

As it can be noticed in Figure 4, a decrease in channel length results a significant rise in 1/f noise.

Modeling results proves that the $1 / f$ noise is more significant for small lengths [23] [24]. This phenomenon is due to variation of channel resistance as well as variation in access resistances of gate $\left(R_{g}\right)$ and source $\left(R_{s}\right)$ [25]. In fact, a decrease in size gate causes more variation of canal resistance, hence, an increase in $1 / f$ noise. This is justified by the fact that the influence of the access resistances appears especially in strong inversion when the channel resistance decreases [25]-[27].

\subsection{Impact of the Insulator Thickness}

Reducing the insulator thickness remains a key lever to improve the performance of the ISFET based microsensors. Figure 5 shows the significant impact of the insulator thickness on the $1 / f$ noise.

As it can be noticed from Figure 5(a) and Figure 5(b), the flicker noise increases by reducing the insulator thickness. This increase can be attributed to the increase in noise leakage by direct tunneling. Indeed, the reduction of the insulator thickness causes an increase in the gate depletion, gate dopant penetration into the channel region, and the leakage current for direct tunneling increases, which leads to an increase of $1 / f$ noise [28]. 


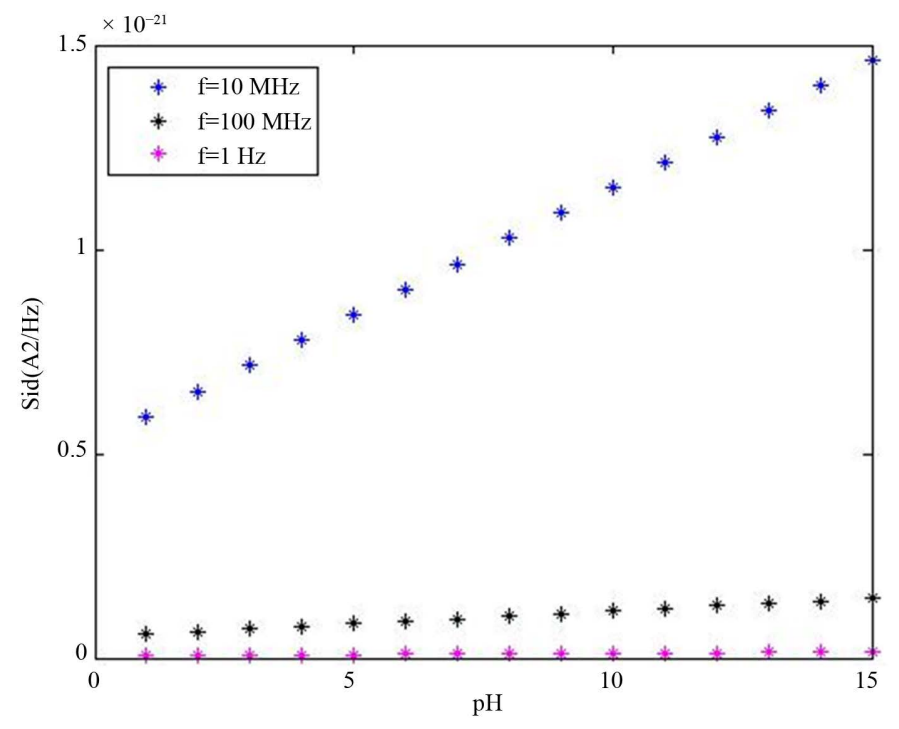

Figure 2. Variation of the spectral noise density of ISFET based $\mathrm{pH}$ at different frequencies $f=100 \mathrm{MHz}, 10 \mathrm{MHz}$ and $1 \mathrm{~Hz}$.

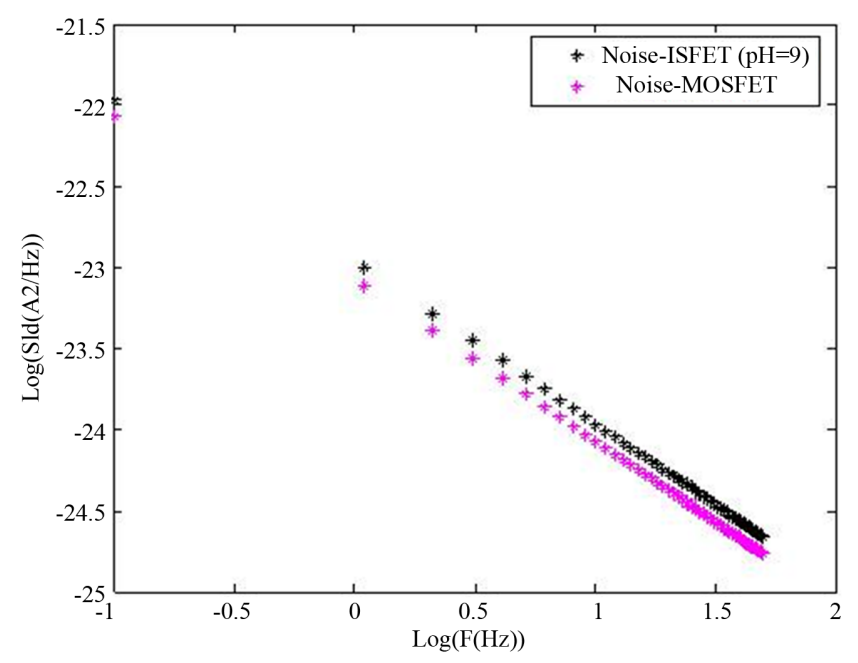

Figure 3. The flicker noise associated to the ISFET sensors towards the one of the MOSFET device.

\subsection{Influence of Temperature}

The temperature effect on the ISFET behavior is classified into two classes: influence resulting from the electronic component (MOSFET) and another due to the electrochemical component. This latter is function of the reference electrode, the electrolyte and the potentials of interface. To study the effect of temperature on the electrochemical component we modeled the potential behavior of the electrolyte/insulator $\left(\psi_{0}\right)$ interface for a wide range of temperature (from $295 \mathrm{~K}$ to $335 \mathrm{~K}$ ). The surface potential $\psi_{0}$ depends on the type of the sensitive membrane, the electrolyte $\mathrm{pH}$ and the operating temperature [29].

Figure 6 shows that the potential electrolyte/insulator interface increases with increasing the temperature. Indeed the sensitivity of the micro-ISFET sensor increases as a function the temperature as result of the increasing in the mass transfer and the activation of electrochemical reactions. Figure 7 shows that for $\mathrm{pH}=5$ the spectral noise density of ISFET decreases with increasing the temperature. On the contrary, when $\mathrm{pH}=7$ the flicker noise increase with temperature. This behavior may be due, in addition to the instability of the FET structure as 


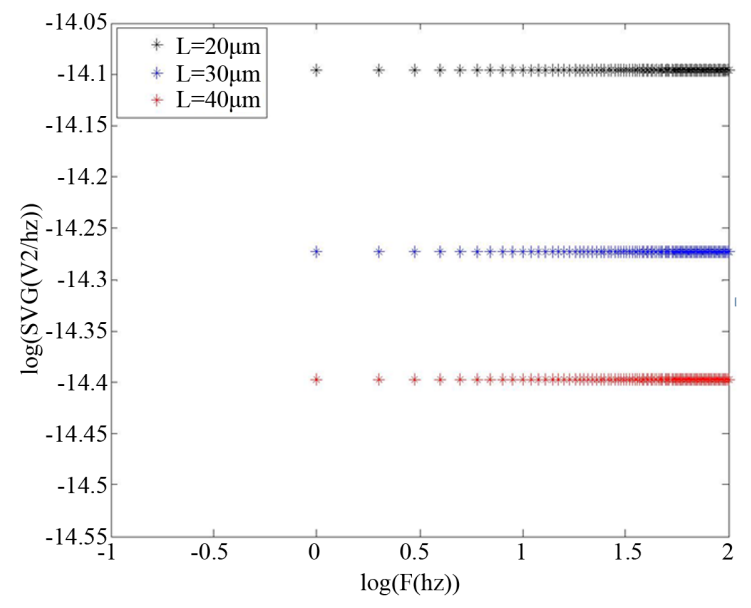

(a)

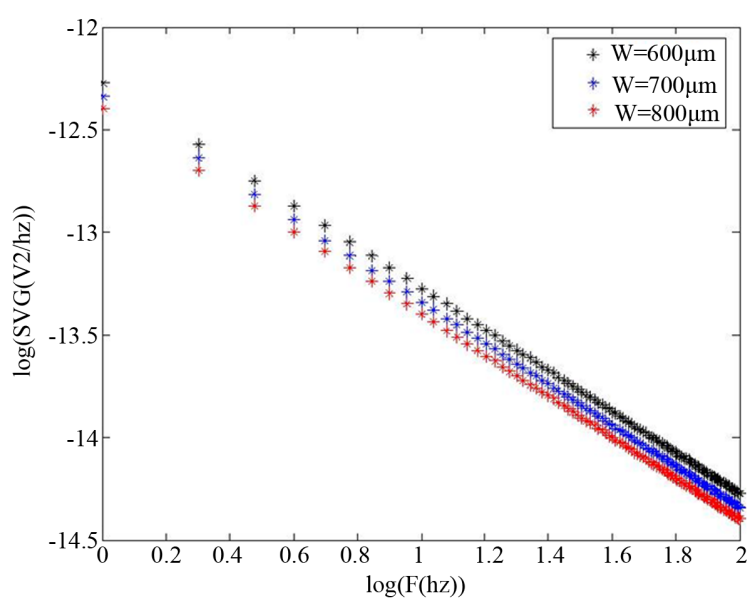

(b)

Figure 4. (a) $S_{V_{g}}$ noise density as a function of frequency for different channel length and fixed width; (b) $S_{V_{g}}$ noise density for different width and a fixed length.

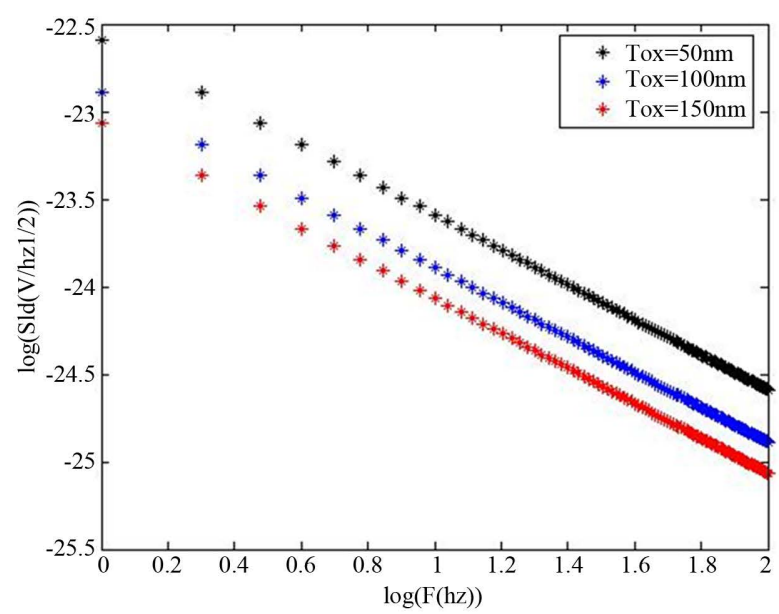

(a)

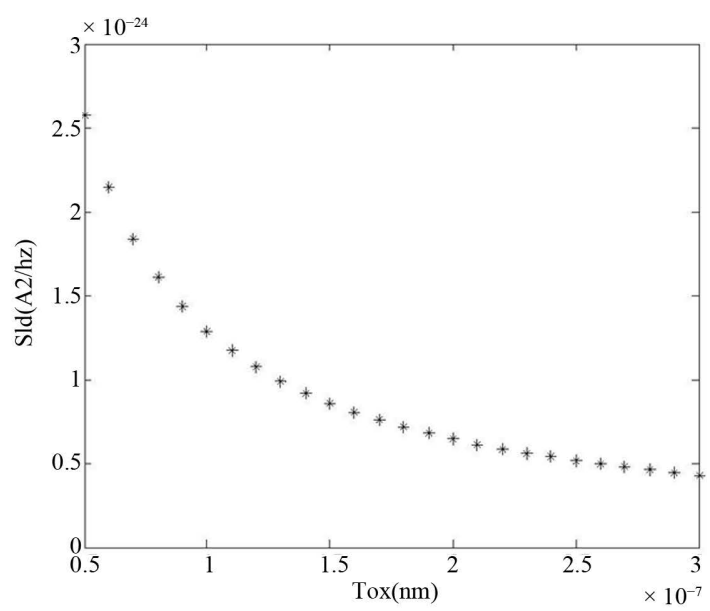

(b)

Figure 5. (a) Shift of the spectral noise density of the ISFET according to the frequency for various insulator thicknesses (Tox $=100 \mathrm{~nm}, 200 \mathrm{~nm}$ and $300 \mathrm{~nm}$ ); (b) Evolution of noise as a function of Tox.

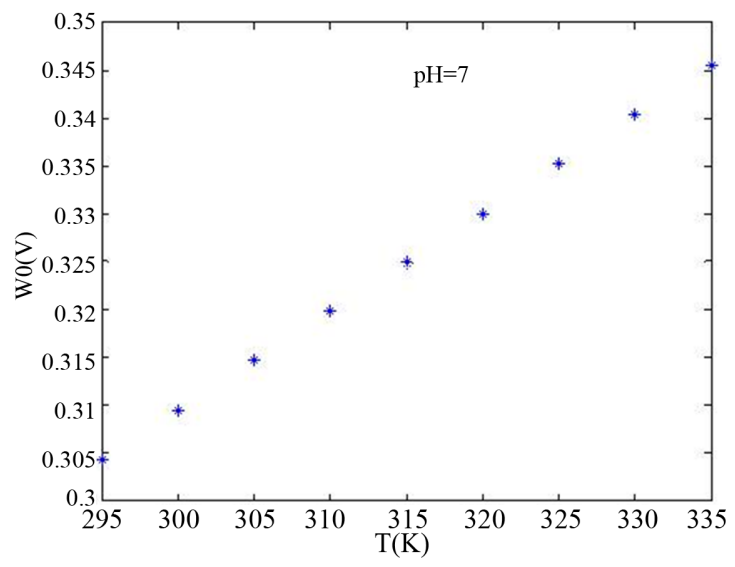

Figure 6. The potential interface shift as function of the temperature in $\mathrm{pH}=7$. 
function of temperature, to the variation of the noise in the electrode-electrolyte interface. Thus, more the electrolyte is less acid more the ion transfer is favored.

\section{Signal Conditioning}

Various studies have turned to the use and the development of differential circuits in order to improve the ISFET sensitivity and reduce the undesirable effects specially the temperature. Differential measurement is a method using an ISFET sensor sensitive to the detected species and a reference Field Effect Transistor. The Reference FET (ReFET) should in ideal case show insensitivity to all species present in the sample solution [30].

In order to investigate the noise generated by different conditioning circuit, we implemented an ISFET macro-model in TopSpice and we simulated the total noise of the system. Figure 8 summarizes the principle of ISFET macro-model. The macro-model is defined by the association of a $\mathrm{V}_{\mathrm{pH}}$ function to the MOSFET device. The $\mathrm{V}_{\mathrm{pH}}$ function is defined in terms of the potential reference $\left(\mathrm{E}_{\mathrm{ref}}\right)$ and the surface potential $\left(\psi_{0}\right)$. We previously used this macro-model to simulate the outputs sensor with different conditioning circuits [31]-[33] and it was shown that the Wheatstone bridge one can ensure the better temperature compensation [34] (in press). In this present work, we modeled the total noise of the same circuit (Figure 9(a)) discussed in [34] (in press). The normalized modeling results are illustrated in Figure 9(b). As it can be seen, the 1/f noise system increases with

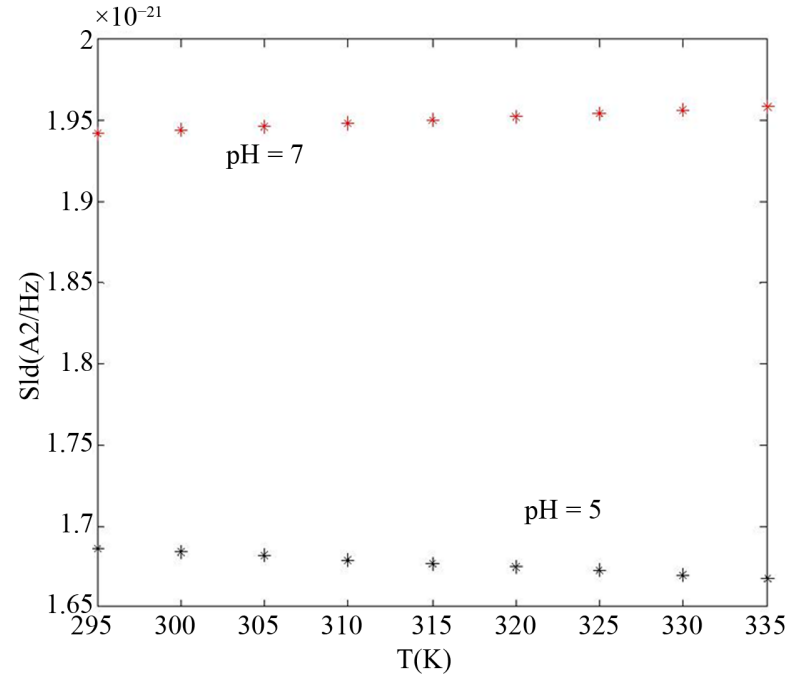

(a)

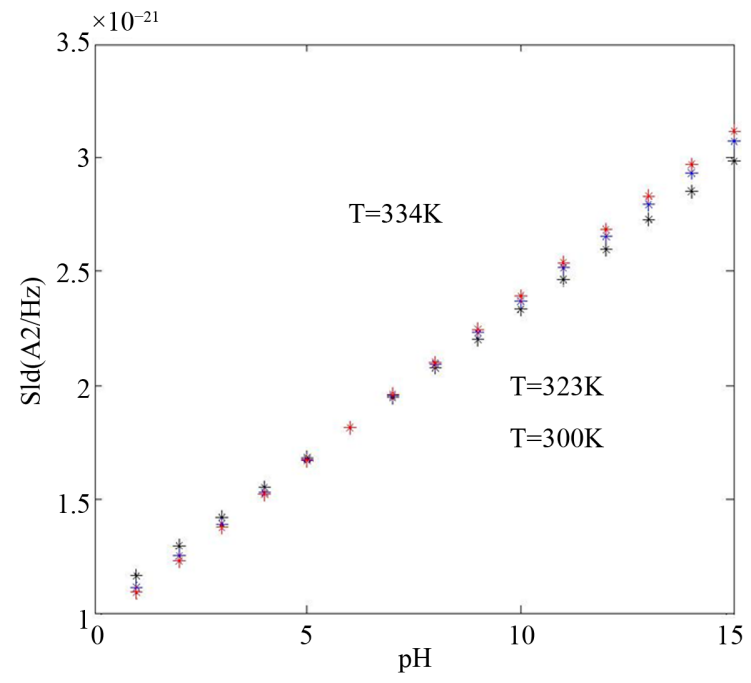

(b)

Figure 7. (a) Behavior of the spectral density of the $1 / f$ noise $S_{\text {id }}$ as a function of temperature for $\mathrm{pH}=5$ and $\mathrm{pH}=7$; (b) Shift of $\mathrm{S}_{\mathrm{id}}$ according to $\mathrm{pH}$ for different temperatures $\left(\mathrm{T}=27^{\circ} \mathrm{C}, 50^{\circ} \mathrm{C}\right.$ and $\left.60^{\circ} \mathrm{C}\right)$.
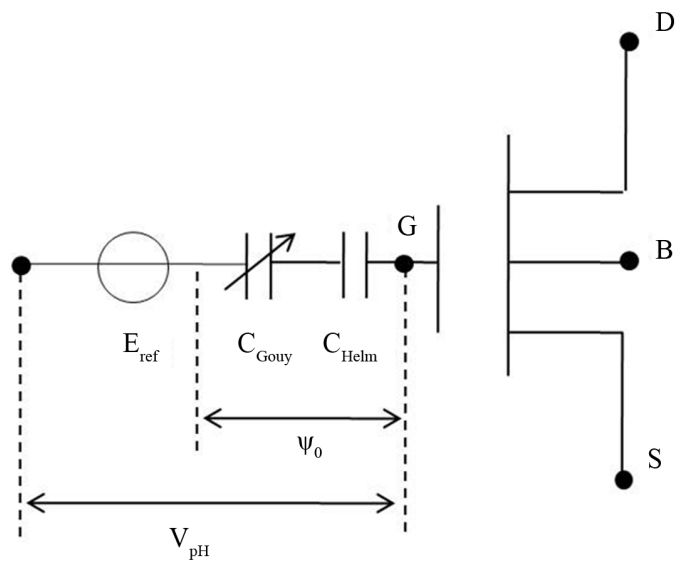

Figure 8. ISFET macro-model. 


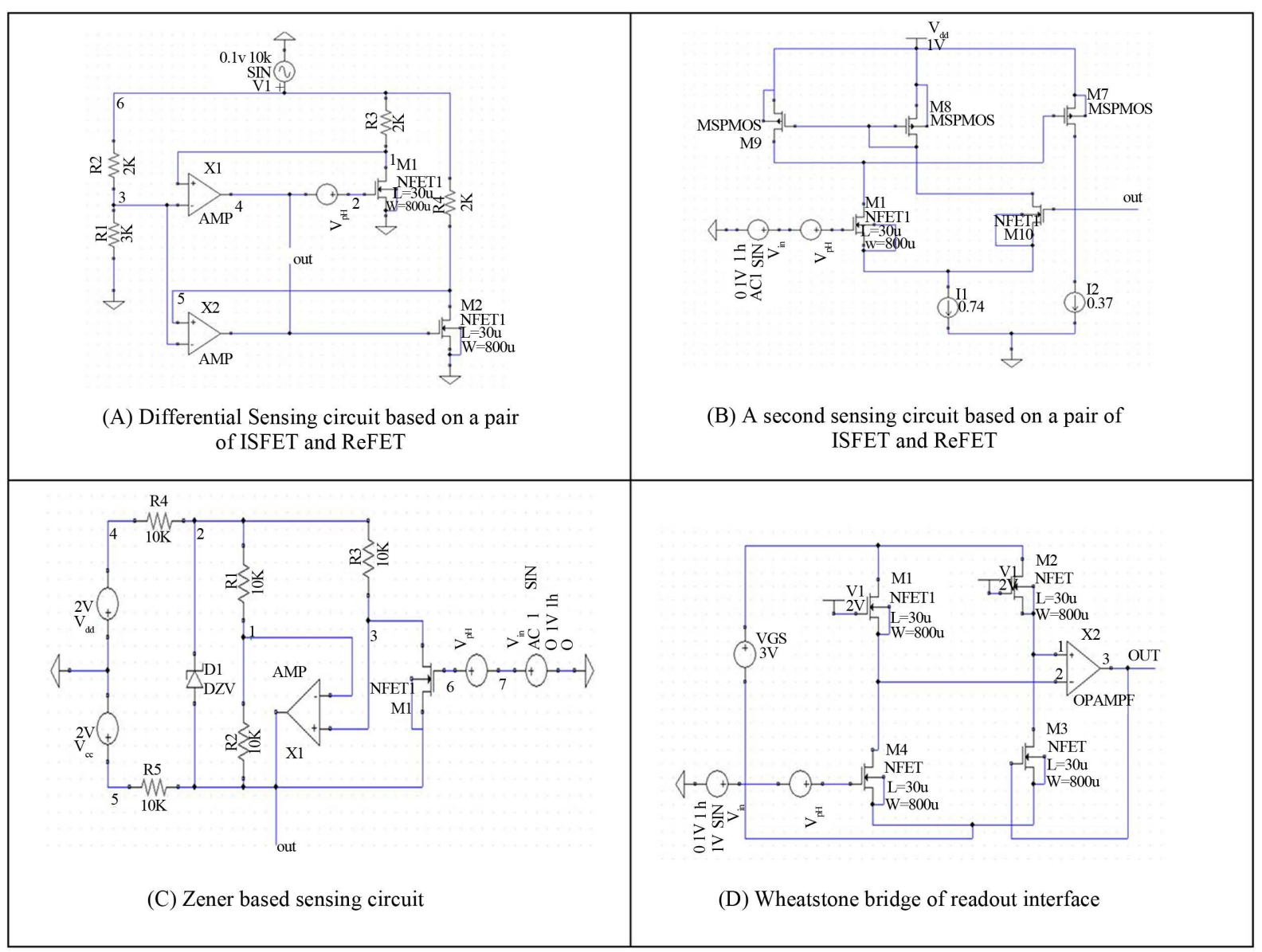

(a)

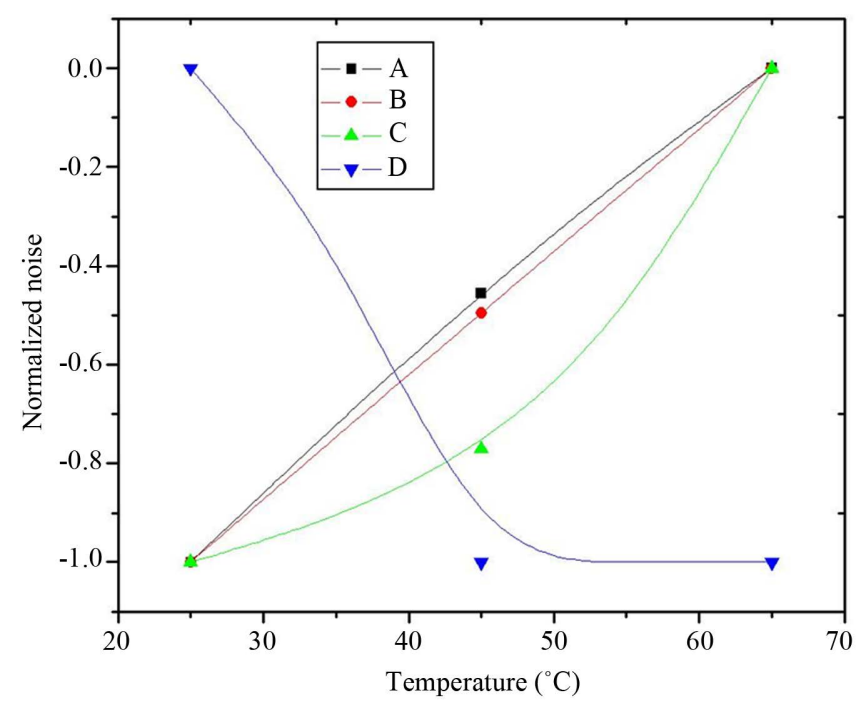

(b)

Figure 9. (a) The different modeled conditioning circuits; (b) The normalized noise of each conditioning circuits.

temperature for the first three circuits. However, for the Wheatstone bridge circuit, the $1 / f$ noise decreases strongly with the temperature. Therefore, this latter circuit is the most appropriate in the strategy of $1 / f$ noise reduction. This result is in good agreement with the results found in [34]. We conclude that the Wheatstone bridge 
circuit allows both the better reduction of $1 / f$ noise and the better thermal compensation.

\section{Conclusion}

In this piece of work, we modeled the $1 / f$ noise source in the ISFET microsensors. We proved the dependency of $1 / f$ low-frequency noise on $\mathrm{pH}$ buffer. We found that the contribution of the $\mathrm{pH}$ solution appeared especially at low frequencies. By increasing the frequency, the effect of $\mathrm{pH}$ on the $1 / f$ noise decreases. We also confirmed the contribution of the MOS structure at low-frequency noise. Indeed, the channel dimensions and the insulator thickness are the most important $1 / f$ noise sources for MOS component. The study of different measurement circuits developed to the temperature compensation proves that the Wheatstone bridge circuit is also the most appropriate to reduce the $1 / f$ noise.

\section{Acknowledgements}

This work was partially supported by the NATO Science for Peace (SFP) Project CBP.NUKR.SFP 984173 and FP7-PEOPLE-2012-IRSES No 318053: SMARTCANCERSENS project.

\section{References}

[1] Fernandes, P.G., Stiegler, H.J., Zhao, M., Cantley, K.D., Obradovic, B., Chapman, R.A., Wen, H.C., Mahmud, G. and Vogel, E.M. (2012) SPICE Macromodel of Silicon-On-Insulator-Field-Effect-Transistor-Based Biological Sensors. Sensors and Actuators B, 161, 163-170. http://dx.doi.org/10.1016/j.snb.2011.10.002

[2] Chang, K.M., Chang, C.T., Chao, K.Y. and Lin, C.H. (2010) A Novel pH-Dependent Drift Improvement Method for Zirconium Dioxide Gated pH-Ion Sensitive Field Effect Transistors. Sensors, 10, 4643-4654. http://dx.doi.org/10.3390/s100504643

[3] Bergveld, P. (2003) Thirty Years of ISFETOLOGY What Happened in the Past 30 Years and What May Happen in the Next 30 Years. Sensors and Actuators B, 88, 1-20. http://dx.doi.org/10.1016/S0925-4005(02)00301-5

[4] Clément, N., Nishiguchi, K., Dufreche, J.F., Guerin, D., Fujiwara, A. and Vuillaume, D. (2011) A Silicon Nanowire Ion-Sensitive Field-Effect-Transistor with Elementary Charge Sensitivity. Physics Letters, 98, 14104-14109.

[5] Deen, M.J., Shinwari, M.W. and Ranuarez, J.C. (2006) Noise Consideration in Field-Effect Biosensors. Journal of Applied Physics, 100, 1074-1082. http://dx.doi.org/10.1063/1.2355542

[6] Chung, W.Y., He, F.S., Yang, C.H. and Wang, M.C. (2005) Drift Response Macromodel and Readout Circuit Development for ISFET and Its H Sensing Applications. Journal of Medical and Biological Engineering, 26, 29-34.

[7] Sibbald, A. (2006) A Chemical-Sensitive Integrated-Circuit: The Operational Transducer. Sensors and Actuators, 7, 23-38. http://dx.doi.org/10.1016/0250-6874(85)87003-7

[8] Chung, W.Y., Lin, Y.T., Pijanowska, D.G., Yang, C.H., Wang, M.C., Krzyskow, A. and Torbicz, W. (2006) New ISFET Interface Circuit Design with Temperature Compensation. Microelectronics Journal, 37, 1105-1114. http://dx.doi.org/10.1016/j.mejo.2006.05.001

[9] Morgenshtein, A., Boreysha, L.S., Dinnar, U., Jakobson, C.G. and Nemirovsky, Y. (2004) Wheatstone-Bridge Readout Interface for ISFET/REFET Applications. Sensors and Actuators B, 98, 18-27. http://dx.doi.org/10.1016/j.snb.2003.07.017

[10] Haemmerli, A., Janata, J. and Brophy, J.J. (1982) Equilibrium Noise in Ion Selective Field Effect Transistors. Journal of the Electrochemical Society, 129, 2306-2312. http://dx.doi.org/10.1149/1.2123500

[11] Hassibi, A., Navid, R., Dutton, R.W. and Lee, T.H. (2004) Comprehensive Study of Noise Processes in Electrode Electrolyte Interfaces. Journal of Applied Physics, 96, 1074-1082. http://dx.doi.org/10.1063/1.1755429

[12] Jakobson, C.G. and Nemirovsky, Y. (1999) 1/f Noise in Ion Sensitive Field Effect Transistor from Subthreshold to Saturation. IEEE Transactions on Electron Devices, 46, 259-261. http://dx.doi.org/10.1109/16.737468

[13] Jakobson, C.G., Feinsod, M. and Nemirovsky, Y. (2000) Low Frequency Noise and Drift in Ion Sensitive Field Effect Transistors. Sensors and Actuators B, 68, 134-139. http://dx.doi.org/10.1016/S0925-4005(00)00473-1

[14] Hsu, S.T. (1970) Surface State Related l/f Noise in Mos Transistors. Solid-State Electronics, 13, 1451-1459. http://dx.doi.org/10.1016/0038-1101(70)90081-X

[15] Berz, F. and Prior, C.G. (1971) Test of McWhorter's Model of Low-Frequency Noise in Si MOSTs. Microelectronics and Reliability, 10, 429-433. http://dx.doi.org/10.1016/0026-2714(71)90101-6

[16] Hooge, F.N. (1994) l/f Noise Sources. IEEE Transactions on Electron Devices, 41, 1926-1935. http://dx.doi.org/10.1109/16.333808 
[17] Vandamme, L.K.J. (1980) Model for 1/f Noise in MOS Transistor Biased in the Linear Region. Solid-State Electronics, 23, 317-323. http://dx.doi.org/10.1016/0038-1101(80)90198-7

[18] Hafez, I.M., Ghibaudo, G. and Balestra, F. (1989) Numerical and Analytical Modelling of Non Ohmic MOSFET Operation at Liquid Helium Temperature. Solid-State Electronics, 32, 861-865. http://dx.doi.org/10.1016/0038-1101(89)90063-4

[19] Hafez, I.M., Ghibaudo, G. and Balestra, F. (1990) A Study of Flicker Noise in MOS Transistors Operated at Room and Liquid Helium Temperatures. Solid-State Electronics, 33, 1525-1529. http://dx.doi.org/10.1016/0038-1101(90)90132-X

[20] Ghibaudo, G., Roux, O., Nguyen-Duc, C., Balestra, F. and Brini, J. (1991) Improved Analysis of Low Frequency Noise in Field-Effect MOS Transistors. Physica Status Solidi (a), 124, 571-581.

[21] Humenyuk, I., Torbiero, B., Assié-Souleille, S., Colin, R., Dollat, X., Franc, B., Martinez, A. and Temple-Boyer, P. (2006) Development of pNH4-ISFETS Microsensors for Water Analysis. Microelectronics Journal, 37, 475-479. http://dx.doi.org/10.1016/j.mejo.2005.09.024

[22] Das, M.P. and Bhuyan, M. (2013) Modeling of pH Dependent Electrochemical Noise in Ion Sensitive Field Effect Transistors ISFET. Sensors \& Transducers, 149, 102-108.

[23] Ioannidis, E.G., Dimitriadis, C.A., Haendler, S., Bianchi, R.A., Jomaah, J. and Ghibaudo, G. (2012) Improved Analysis and Modeling of Low-Frequency Noise in Nanoscale MOSFETs. Solid-State Electronics, 76, 54-59. http://dx.doi.org/10.1016/j.sse.2012.05.035

[24] Boutchacha, T. and Ghibaudo, G. (2011) Improved Low Frequency Noise Model for MOSFET Operated in Non-Linear Region. Microelectronic Engineering, 88, 1280-1282. http://dx.doi.org/10.1016/j.mee.2011.03.086

[25] Rumyantsev, S.L., Pala, N., Shur, M.S., Gaska, R., Levinshtein, M.E., Asif Khan, M., Simin, G., Hu, X. and Yang, J. (2001) Low Frequency Noise in GaN Metal Semiconductor and Metal Oxide Semiconductor Field Effect Transistors. Journal of Applied Physics, 90, 310-314. http://dx.doi.org/10.1063/1.1372364

[26] Ghibaudo, G. (1997) Critical MOSFETs Operation for Low Voltage/Low Power IC’s: Ideal Characteristics, Parameter Extraction, Electrical Noise and RTS Fluctuations. Microelectronic Engineering, 39, 31-57. http://dx.doi.org/10.1016/S0167-9317(97)00166-4

[27] Jin, X.D., Ou, J.J., Chen, C.H., Liu, W., Deen, M.J., Gray, P.R. and Hu, C. (1998) An Effective Gate Resistance Model for CMOS RF and Noise Modeling. IEDM'98. Technical Digest, IEEE International Electron Devices Meeting, San Francisco, 6-9 December 1998, 961-964.

[28] Singh, H., Sarin, R.K. and Singh, S. (2010) Analysis and Modeling of 1/f Noise in MOSFETs for Circuit Applications: The Joint Effect of Channel Length and Conducting Slab Resistance. Canadian Journal on Electrical and Electronics Engineering, 1, 116-121.

[29] Chou, J.C. and Wang, Y.F. (2001) Temperature Characteristics of a-Si:H Gate ISFET. Materials Chemistry and Physics, 70, 107-111. http://dx.doi.org/10.1016/S0254-0584(00)00469-7

[30] Skowronska-Ptasinska, M., Van Der Wal, P.D., Van Den Berg, A., Bergveld, P., Sudholter, E.J.R. and Reinhoudt, D.N. (1990) Reference Field Effect Transistor Based on Chemically Modified ISFETs. Analytica Chimica Acta, 230, 67-73. http://dx.doi.org/10.1016/S0003-2670(00)82762-2

[31] Sibbald, A. (1985) A Chemical-Sensitive Integrated-Circuit: The Operational Transducer. Sensors and Actuators, 7, 23-38. http://dx.doi.org/10.1016/0250-6874(85)87003-7

[32] Chung, W.Y., Lin, Y.T., Pijanowska, D.G., Yang, C.H., Wang, M.C., Krzyskow, A. and Torbicz, W. (2006) New ISFET Interface Circuit Design with Temperature Compensation. Microelectronics Journal, 37, 1105-1114. http://dx.doi.org/10.1016/j.mejo.2006.05.001

[33] Morgenshtein, A., Boreysha, L.S., Dinnar, U., Jakobson, C.G. and Nemirovsky, Y. (2004) Wheatstone-Bridge Readout Interface for ISFET/REFET Applications. Sensors and Actuators B, 98, 18-27. http://dx.doi.org/10.1016/j.snb.2003.07.017

[34] Azzouzi, S., Chermiti, J., Ben Ali, M., Dridi, C., Errachid, A. and Jaffrezic-Renault, N. (2014) TopSPICE Simulations for Temperature Compensation of ISFET/MEMFET Micro-Sensor. Sensors \& Transducers. (in press) 
Scientific Research Publishing (SCIRP) is one of the largest Open Access journal publishers. It is currently publishing more than 200 open access, online, peer-reviewed journals covering a wide range of academic disciplines. SCIRP serves the worldwide academic communities and contributes to the progress and application of science with its publication.

Other selected journals from SCIRP are listed as below. Submit your manuscript to us via either submit@scirp.org or Online Submission Portal.
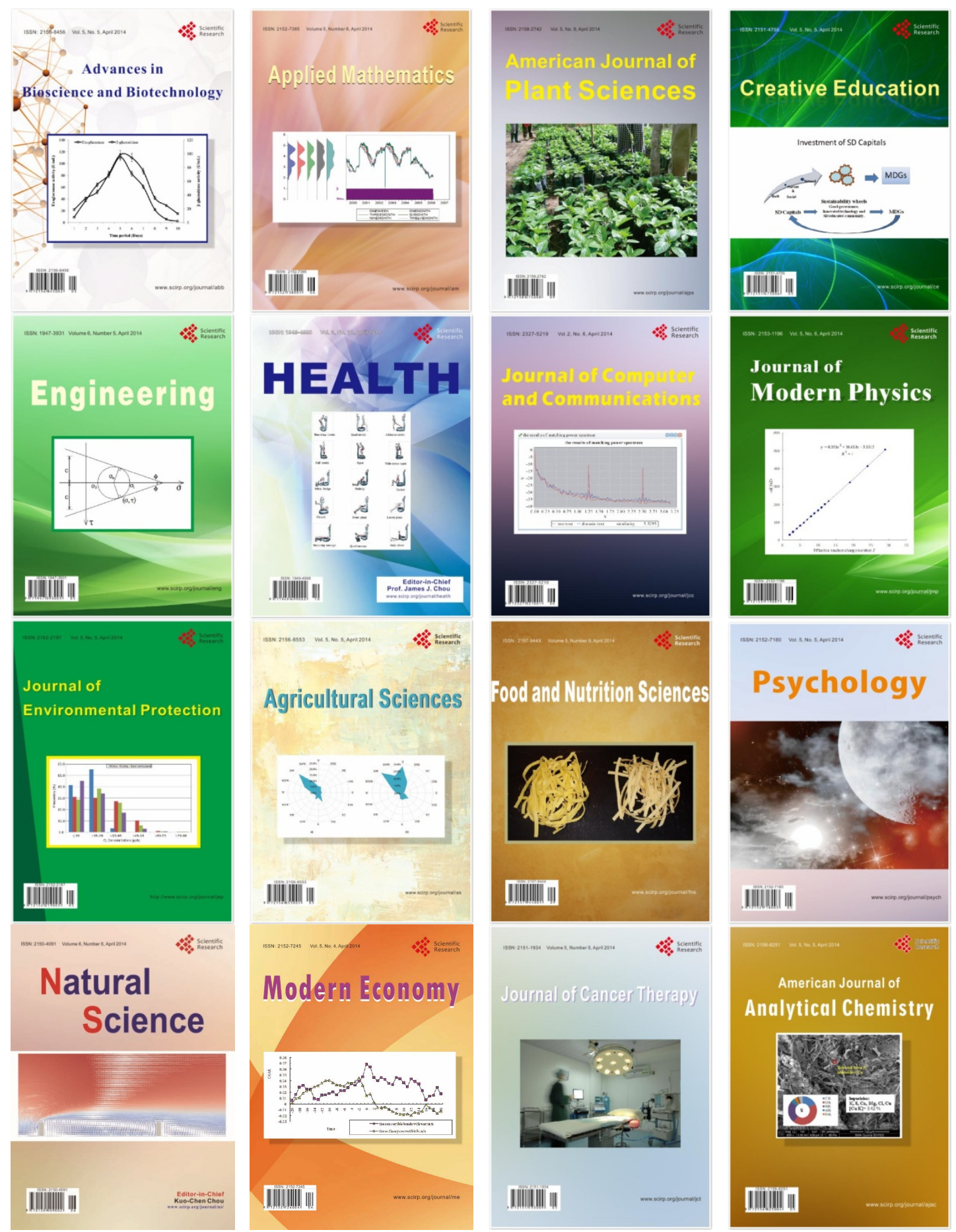